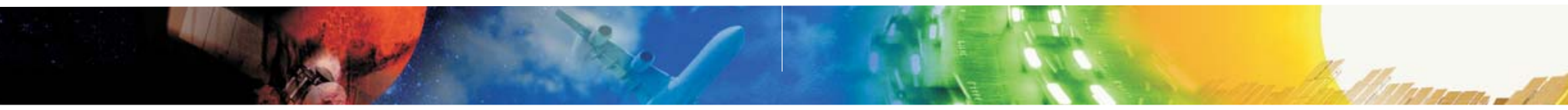

\section{Raman Spectroscopic Investigation of Plasma-Sprayed Zirconia-Based Electrolytes}

A. Haug, ${ }^{a}$ C. Christenn, ${ }^{a}$ B.-E. Schuster, ${ }^{a}$ G. Schiller, ${ }^{a}$ T. Chassé, ${ }^{b}$ K. A. Friedrich ${ }^{a}$

\section{Introduction}

Solid oxide fuel cells (SOFC) operating in the temperature range between $800-1000^{\circ} \mathrm{C}$ are devices converting directly chemical energy into electrical energy. The SOFC electrolyte layer typically consisting of yttria-stabilized zirconia (YSZ) was prepared using atmospheric plasma spraying technology. Plasma spraying is a cost-effective technique for the production of functional layers in SOFCs and allows the optimization of the layers' porosity that affects the fuel cell performance (e.g.,
life-time). Raman spectroscopy is a powerful tool for the investigation of structural features, for example, crystallinity, molecular orientation, and phase composition, especially of inorganic thin films. In order to get further information concerning the thin-film properties of plasma-sprayed zirconia-based electrolytes X-ray diffraction (XRD) as well as scanning electron microscopy (SEM) were applied. In this study we show that depending on the preparation conditions the crystal growth and the density of the plasma-sprayed thin films can be influenced significantly. Therefore Raman spectra as well as XRD and SEM pictures show subtle differences concerning the crystallinity of various samples.

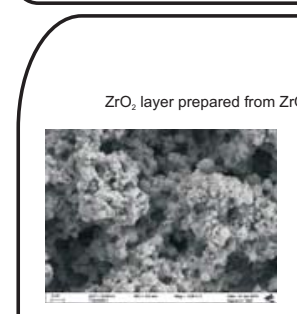

$\mathrm{ZrO}_{2}$ layer prepared from $\left.\mathrm{ZrO}(\mathrm{NO})_{2}\right), 10 \mathrm{wt} \%$ after sintering at $850^{\circ} \mathrm{C}$ for $450 \mathrm{~h}$
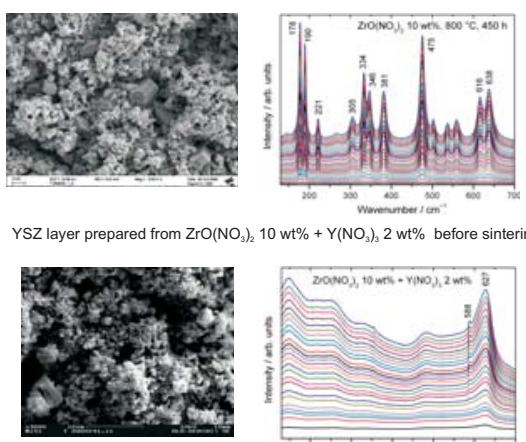

YSZ after sintering
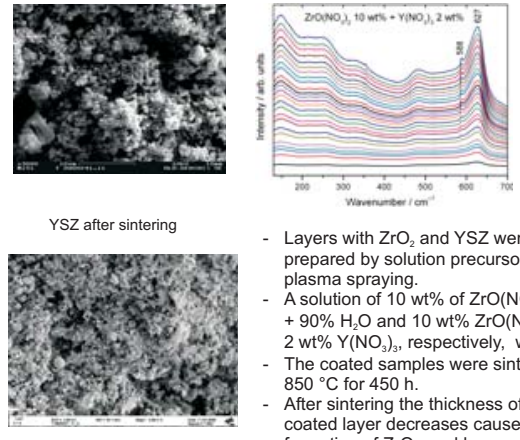

Layers with $\mathrm{ZrO}_{2}$ and $\mathrm{YSZ}$ were prepared by solution precursor

A solution of $10 \mathrm{wt} \%$ of $\mathrm{ZrO}\left(\mathrm{NO}_{3}\right)_{2}$ ( (n) $850^{\circ} \mathrm{C}$ for $450 \mathrm{O}$

After sintering the thickness of the coated layer decreases caused by the formation of $\mathrm{ZrO}_{2}$ and les porous layer was formed.
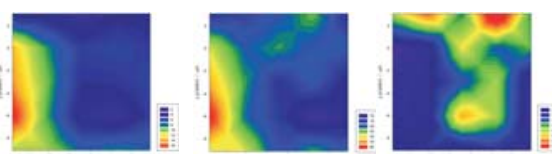

Contour plots (top and bottom) Left: tetragonal phase (616 and $\left.639 \mathrm{~cm}^{-1}\right)$

Right: ratio of monoclinic and tetragonal phase (peak intensities)
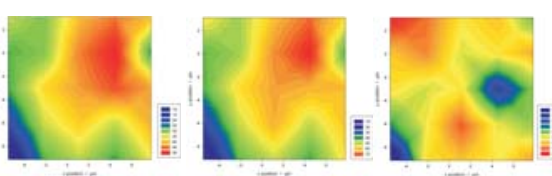
Due to sintering of the $\mathrm{ZrO}_{2}$ layers prepared from
$\mathrm{ZrO}\left(\mathrm{NO}_{3}\right)_{2} 10 \mathrm{wt} \%$ a change in the morphology formation of caskets - can be observed. In contrast, the sintered layers prepared from $\mathrm{ZrO}\left(\mathrm{NO}_{3}\right)_{2}$ $10 \mathrm{wt} \%+\mathrm{Y}\left(\mathrm{NO}_{3}\right)_{3} 2 \mathrm{wt} \%$ did not show this effect after $450 \mathrm{~h}$ at $850^{\circ} \mathrm{C}$

(mapping) were recorded $(12 \times 12 \mu \mathrm{m})$. A high variation of the signal intensities roughness.

The main peaks in the obtained spectra from the resulting $\mathrm{ZrO}_{2}$ before and after sintering can be assigned as following: monoclinic phase: 178, 190 and $476 \mathrm{~cm}^{-1}$; tetragonal phase: 616 and $639 \mathrm{~cm}^{-1}$. (reaction of ZIO(NO) $10 w+\%+Y(N O), 2 w t \%)$ at 627 $\mathrm{cm}^{-1}$ is assigned to cubic $Y S Z$. The ratio between both Z $\mathrm{YSZ}$. homogeneous due to sinterin

The reflectivity seems to be related to the ratio of both phases, at higher monoclinic quotient lower intensities of the spectra were recorded

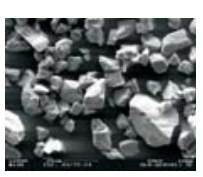

SEM image of conventional powder
$9.5 \mathrm{~mol} \% \mathrm{YSZ}\left(\mathrm{ZrO}_{2}-\mathrm{Y}_{2} \mathrm{O}_{3} 85 / 15\right)$
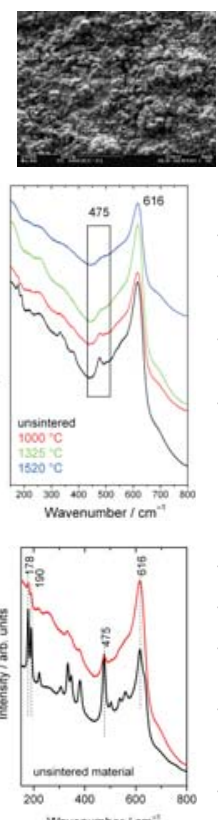

Method B

The second way to prepare YSZ layers is to use atmospheric plasma spraying. or receiving free-standing spralytes, the powder was which were treated with $\mathrm{HCl}$ to remove the steel substrate.

Due to the spraying proces the morphology of the powder changes significantly, typically plasma-sprayed melted particles, and the material recrystallizes.

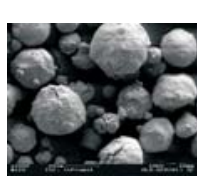

SEM image of YSZ (10 mol\%)

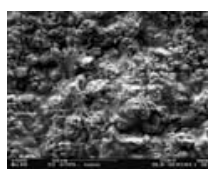

The spectra on the left were measured after sintering of the layer prepared from conventional powder at various temperatures. zintering temperature. The sintering temperature influences the homogeneity of the surface ( $\mathrm{ZrO}_{2} / \mathrm{YSZ}$ )

Comparison of two different spectra from the same surface (unsintered): $\mathrm{ZrO}_{2}$ as well as cubic YSZ can be detected on the surface [penetration depth of the laser $(\lambda=442 \mathrm{~nm})$ approx. $10 \mathrm{~nm}]$.
$\mathrm{ZrO}_{2}$ possesses a low ion conductivity, YSZ possesses a better ion conductivity. With lower content of $\mathrm{ZrO}_{2}$ (peak at $475 \mathrm{~cm}^{-1}$ decreases) in the sample the ion conductivity increases.

The spectra on the left were measured at two different positions of the unsintered layer prepared from conventional powder. The band structure from $150-800 \mathrm{~cm}^{-1}$ is characteristic of the cubic YSZ phonon modes.

Dom peak at $616 \mathrm{~cm}^{-1}$ is characteristic fort he $F_{29}$ phase of the cubic YSZ structure. This band corresponds thetching of the oxygen bound to zirconium.

$\mathrm{ZrO}_{2}$ : the monoclinic $\mathrm{ZrO}$ presents very well defined peaks, the more intense of which are located at $177,190,475 \mathrm{~cm}^{-1}$. That means that mainly the monoclinic phase is present. The presence of the

tetragonal phase can be excluded.

The unsintered layer prepared from the conventional powder shows an inhomogeneous composition related to complete different Raman

\section{Experimental Set-up}

e performed on a confocal Raman microscope LabRAM HR800 (Horiba Jobin-Yvon). The samples were irradiated with a He-Cd laser $(\lambda=442 \mathrm{~nm})$. The spectra were obtained with a laser power of $80 \mathrm{~mW}$, a hole of $1000 \mu \mathrm{m}$, and a resolution of $0.4 \mathrm{~cm}^{-1}$. The SEM images were recorded on a Gemini Ultra Plus (Zeiss) and Gemini LEO 982 (Zeiss).

Materials for Plasma Spraying

Two commercial yttria-stabilized zirconia were used as raw powder for preparing electrolyte layers by the direct current (DC) plasma spray process [7]. A conventional $9.5 \mathrm{~mol} \% \mathrm{YSZ}\left(\mathrm{ZrO}_{2}-\mathrm{Y}_{2} \mathrm{O}_{3} 85 / 15\right.$; fused and crushed; $\mathrm{H}$. Starck, 03/75-24) with a mean particle size between 5 and $22 \mu \mathrm{m}$ and a $10 \mathrm{~mol} \%$ YSZ nanostructured powder agglomerated to 5-20 $\mu \mathrm{m}$ particles, were used.

\section{Acknowledgment}

The authors gratefully acknowledge Ina Plock and Dr.-Ing. Robert Ruckdäschel for recording SEM images and Dr. Mathias Schulze an and helpful discussions.

\section{References}

[1] Barberis, C; Merle-Méjan, T.; Quintard, P. J. Nucl. Mater. 1997, 246, 232-243 Cheng, Z.; Liu, M. Solid State lonics $2007,178,925-935$

Pomfret M. B. Stoltz, C. Varughese, B. Walker. R. A. Anal Chem. 2005, 77,

[4] Hattori, M. Takeda, Y. Sakaki, Y. Nakanishi, A. Ohara, S. Mukai, K. Lee, J.-H.; Fukui, T. J. Power Sources 2004, 126, 23-27

Hattori, M.; Takeda, Y.; Lee. J.-H.; Ohara, S.; Mukai, K.; Fukui, T.; Takahashi, S.

92, 53-56, 1264-126 . T. Therm. Spray. Technol. 2006, 15, 617-622, 